\title{
The Challenges of Knowledge Workers Management
}

\author{
Lukasz Pietrzak*
}

\begin{abstract}
Summary
The paper focuses on factors which influence productivity and creativity of knowledge workers but it also treats about managing teams made up of knowledge workers. Main topics that have been analyzed include workers autonomy, rewarding, motivation, communication, organizational climate, organizational structure, team building, organizational processes, specialization and also clear responsibility allocation. In order to combine great results with knowledge workers satisfaction, it is necessary for managers to be well familiarized with mentioned topics and to know how to use them.
\end{abstract}

Keywords: management, Knowledge worker, Productivity, Creativity, IT industry

JEL: M1, M15, M5, M54

\section{INTRODUCTION}

Today, the number of knowledge workers constantly increases. They constitute about $40 \%$ of the whole world's workforce (Drucker, 2002). People whose advantages are knowledge and learning capabilities and who focus on quality are vital for organizations to build competitive advantage (Oskarsdottir, 2017).

In the 20th century the most valuable asset of a company was its production equipment, while in the 21 st century it is and it will be knowledge workers. (Drucker, 1999). Today's managers face a great deal of challenges connected with managing knowledge workers. However, workers also expect a lot from their employees and managers. Thus, it is crucial for people managing workers to know how to do it well and efficiently. It is easy to lose a good worker by making simple mistakes but it is extremely difficult to employ a very good one. Therefore, every manager has to know the challenges that come with managing knowledge workers and factors which foster workers' efficiency, creativity and motivation.

\section{KNOWLEDGE WORKER}

A knowledge worker is a person, who does her work with everything she learned during systematic education (ideas, theories, definitions) unlike person who uses manual skills or physical strength (Drucker, 2005). According to another definition, knowledge workers are workers who focus on creating, distributing and making use of the knowledge. They possess very well developed specialist knowledge, wide and strong experience or good education (Davenport, 2005). Natalie Waters (2012) defines knowledge workers as those who use their minds rather than hands to create value.

The first person who noticed the aspect of knowledge in the activities performed by manual workers was Frederick Winslow Taylor (1856-1915). He believed that knowledge meant the way simple movements were put together as a whole, how they were organized and performed. Drucker (1999) even claimed that all economic and social achievements of the 20th century were based, to some extent, on the use of Taylor's method and its refinements. However, methods used to organize manual workers work are not applicable to knowledge workers (Oskarsdottir, 2017).

* Faculty of Management, University of Warsaw, Poland, https://orcid.org/0000-0003-0057-6088, e-mail: pietrzak.lukasz@ gmail.com 
The paper describes three categories of topics connected with work organization of knowledge workers. They are as follows: knowledge workers productivity, knowledge workers creativity and management of teams made up of knowledge workers.

\section{Knowledge Worker Productivity}

According to Drucker (1999), six major factors that influence knowledge worker productivity include:

1. Knowing and understanding the assigned tasks.

2. Independence and autonomy.

3. Innovation as an integral part of the work.

4. Continuous self-improvement and knowledge sharing.

5. High-quality results of the work.

6. Treating knowledge workers as assets of an organization rather than costs.

Smith (2005) in his research of 72 companies from the high-tech sector states that knowledge workers productivity, and consequently the entire company's productivity, is defined by the speed of the new products and services introduction which, in turn, depends on the company's capability to create knowledge.

Oskarsdottir (2017) determines that four main challenges connected with the issue of low knowledge workers productivity from the point of view of organizations involve:

1. The need for gaining information and worker interdependence.

2. Motivation, work engagement and health.

3. Organizational structure and changes in organizations.

4. The nature of knowledge work.

While, eight main challenges connected with the issue of low knowledge workers productivity from the point of view of workers include (Oskarsdottir, 2017):

1. Too heavy demands and insufficient resources.

2. Self-improvement and self-awareness of one's capabilities and needs.

3. Effectiveness.

4. Setting and achieving goals.

5. Full potential fulfillment.

6. More productive thinking.

7. Positive relations and collaborations with coworkers.

8. Motivation.

From the perspective of organizations, the productivity of knowledge workers will increase when the workers perform tasks that create value for the organizations. However, the productivity will decrease if (Oskarsdottir, 2017):

1. The workers perform tasks that do not create value for organizations.

2. The workers perform tasks ineffectively due to lack of knowledge sharing and cooperation with other workers.

3. The workers perform tasks ineffectively because their organization does not cater to their needs.

From the perspective of knowledge workers themselves their productivity will increase when the workers can perform tasks that create value for the organizations effectively and when they can realize their full potential. Nevertheless, the productivity will fall when (Oskarsdottir, 2017) personal worker resources deplete which results in exhaustion and stress and the workers perform activities that do not create value.

Janz (2003) claims that the higher the level of cooperative learning in an organization, the higher the work productivity and the workers' satisfaction form their tasks. There are three characteristics 
of the cooperative learning process (Janz, 2003): positive interdependence, encouraging interactions between team members and group process. He also states that the factors which have a positive influence on the level of cooperative learning are (Janz, 2003) autonomy and organizational climate.

Among the entrepreneurs mistakes in creating the organizational climate that may cause adverse consequences we can list (Glinka, Pasieczny, 2015):

1. Advocating values and norms that are hard to accept by workers or even deemed inappropriate by them.

2. Official advocacy of values and norms that entrepreneurs themselves do not conform to.

3. No connection between advocated norms and behaviors and the system of worker promotion, development and rewarding.

It is worth mentioning that the success of project teams also depends on the number of knowledge workers that make up those teams. The bigger the number of knowledge workers in a project team, the higher the team's productivity (Waters, 2012). Waters claims in his research that a project will be successful if the percentage of knowledge workers in a project team approximates to 63 percent.

\section{Knowledge Worker Creativity}

Similarly to productivity, knowledge workers creativity is one of the factors that determine the success of enterprises and drive their innovation. Knowledge workers creativity depends to a large extent on their knowledge, and this knowledge and its organization in enterprises is a complicated issue. That complexity allows, on the one hand, to gain a competitive advantage of a given company over another, and on the other hand, it involves difficulties in knowledge management (Henard, 2008).

According to Henard (2008), the most fundamental knowledge level, that is the basis for the knowledge pyramid, is the acquired knowledge. This type of knowledge consists of information that is available to others and which also regards issues not directly related to the organization in which the worker is currently working. This knowledge is collected by the worker throughout his whole career and consists of past experience, knowledge sharing with coworkers, trainings and readings. The next level is the unique knowledge (Henard, 2008). It is based on the acquired knowledge but requires more advanced cognitive abilities from the worker. It is the knowledge that is created by making new knowledge combinations that have not been previously noticed by the worker.

The top of the knowledge pyramid is occupied by the creative knowledge (Henard, 2008). It is based on the acquired and unique knowledge and depends on how deep and wide these types of knowledge are. However, creative knowledge is the main source of innovative ideas. This type of thinking goes beyond making connections and combinations between several sources of information. Creative knowledge is about creating completely new ideas and innovative solutions to problems for which there have not been any known solutions so far. An organization that has knowledge workers with this level of thinking may establish a competitive advantage over other organizations.

David Henard (2008) believes that in order to develop creative knowledge in an organization, the following actions should be taken:

1. Allowing workers to deepen and broaden their acquired knowledge.

2. Allowing workers to have contact with different sources of knowledge, also outside the organization.

3. Promoting knowledge sharing practices and training workers in the areas of seeking knowledge outside the organization, e.g. clients product offering.

4. Rewarding the workers who contribute to the expanse of creative abilities in the organization and eliminating bad practices even by penalizing those workers who do not want to share their knowledge.

5. Placing the role of knowledge and creativity high in the organization hierarchy.

6. Knowledge workers should periodically become responsible for a new area for them. 
According to Smith (2005), the organization's creativity manifests itself in the organization's ability to create new knowledge. The key factors that affect this are (Smith, 2005):

1. The level of knowledge of the organization's top management and knowledge workers.

2. Networking between the top management of the organization and the key workers.

3. An organizational climate that supports or suppresses the ability to create new knowledge.

\section{The Management of Teams Consisting of Knowledge Workers}

In order to organize the work of knowledge workers optimally, one should pay attention not only to the individual person, but to the entire team. The work of knowledge workers should be restructured and organized as part of the system (Drucker, 1999).

The issue of recruitment and selection of persons for the project team as well as the choice of the appropriate manager of such a team has a critical impact on the success of the project (Wi, 2009). Hyeongkon Wi (2009) proposed a model for the objective evaluation of candidates' knowledge and their selection for project teams. Worker's knowledge consists of two main elements (Wi, 2009): personal knowledge and knowledge from the worker's network of contacts.

Worker's knowledge assessment process is carried out according to the following algorithm (Wi, 2009):

1. Collecting keywords describing the project.

2. Assessing the level of knowledge of each worker as the sum of comparisons of each keyword describing the project with the keywords appearing in the publications of the researcher (reports, documents, patents, books, etc.) and his network connections resulting from co-creation of these documents.

The project team is selected from among those with the best results, and the team leader is the person who has the best overall score on both knowledge and network connections. In addition to selecting a team leader, the issue of team management is equally important. According to Pearce (2004), when managing knowledge workers, traditional team management by one person is less effective than sharing the leadership among the team members.

Factors that may indicate the need for shared leadership are (Pearce, 2004): a large interdependence of workers in the team, implementation of tasks that require a lot of creativity and implementation of tasks that are complicated.

A very important issue for any organization is the issue of workers turnover. The costs of new recruitments are high for the organization and the resignation of knowledge workers is also associated with the loss of knowledge, and thus the loss of competitive advantage of the organization (Jayasingam, 2016). Moreover, the assumption that knowledge can be separated from the knowledge worker is an erroneous assumption (Howe and Levin, 2007). Therefore, organizations should focus on motivating workers to remain in the organization. According to Jayasingam (2016), workers who display a high degree of emotional commitment to the organization are less likely to change their job.

Factors that have a positive impact on the degree of knowledge worker's emotional commitment to the organization, and hence, the reduction of departures from the organization, are (Jayasingam, 2016): worker appreciation, knowledge sharing culture, autonomy in the performed tasks, management support and fair rewarding and promotions for good performance.

With regard to building knowledge worker's emotional commitment to the organization, Glinka and Pasieczny (2015) indicated that the issue of motivating is one of the most difficult challenges that managers face, regardless of the size of the organization. They believe a good motivation system should include elements from the group of material factors such as salary, bonuses and office equipment, as well as from the group of immaterial factors such as recognition and enabling self-development. Additionally, a two-factor theory of motivation consisting of hygiene factors and motivators should be considered (Herzberg, 1987). 


\section{CONCLUSIONS}

Knowledge workers require a specific approach and they should be managed by specific techniques. The nature of knowledge workers work differs from that of manual workers. Manual workers methods developed over decades do not apply to knowledge workers. Knowledge workers are expected to deliver high-quality work and creativity in creating new knowledge, products and solutions. The tasks they perform are usually complicated ones which require constant development, qualifications improvement and continuous new knowledge acquisition in a rapidly changing environment.

The key aspects that a knowledge workers manager must pay attention to are:

1. A proper definition of tasks and objectives. It is very important to instruct and set tasks, so the worker does everything to bring profit to the organization. It is necessary to eliminate or significantly reduce the tasks that waste the time of knowledge workers. It is imperative to hand over such tasks to workers with lower competencies who are less expensive. However, there cannot be too many tasks entrusted to workers since it would lead to significant losses in workers internal resources, productivity and job satisfaction.

2. Knowledge workers autonomy. Knowledge workers in order to work effectively need a lot of autonomy in their work. The autonomy has also a positive impact on their job satisfaction as well as the perceived level of trust in them, which is crucial for retaining workers in the organization. What is more, the nature of knowledge workers work requires from them to have specialist knowledge and create new knowledge. As specialists in a given field they should be responsible for making all of the decisions in terms of tasks.

3. Climate and organizational culture.An organization should create a climate that encourages and supports cooperation, knowledge sharing and team work. Open and positive atmosphere, the acceptance of the risk resulting from taking up innovative topics and the mutual support provided by workers and the organization have a large impact on the productivity of workers as well as on the level of their job satisfaction.

4. Supporting development, innovation and creative thinking. Knowledge workers are usually motivated to self-develop and gain knowledge. However, it is important that the organization support these initiatives by giving workers opportunities to get certificates, participate in trainings, conferences and funded studies. In addition to expanding workers creativity in this way, workers themselves may consider these initiatives as ways in which the organization cares for them, invests in them and treats them as an asset rather than as a cost. The bonus system in the organization should also be structured in such a way as to reward team activities, successes and knowledge sharing.

5. A proper structure of the team. While building teams, it is worth taking into account the fact that higher productivity is reached by teams with a higher number of knowledge workers. In addition, the evaluation of recruited workers should not only include the verification of their personal knowledge but also their network of contacts. In particular, people holding managerial positions should have a good network of contacts as well as large knowledge in a given area. In case of teams composed almost entirely of knowledge workers and in which there is a high degree of interdependence and the need for high creativity in the implementation of complex tasks, it is worth establishing a shared leadership in the team.

6. Motivation systems. Workers in order to work effectively need proper motivation. Motivation is crucial for them to feel job satisfaction and not to leave the organization. Minimizing the number of knowledge workers departures is important since workers who leave an organization take with them their knowledge and competencies that, despite knowledge management systems, are very difficult to record in a formal way and which are important for the competitive advantage of the organization. That is why it is important to properly appreciate workers whether in the aspect 
of remuneration, facilitating and financing their development and ensuring proper working conditions - either in terms of office conditions, flexible working forms or home office work. Telecommuting may also have a positive impact on workers productivity and may increase their commitment. It is also important to remember about immaterial motivators. Sometimes appreciating the contribution of each worker and telling him that he has done a "good job" can be as important to him as an additional bonus.

7. Creating appropriate working conditions. Workers will be satisfied and work efficiently if they have the appropriate conditions and a high level of personal resources: emotional, physical, social and cognitive. Therefore, it is important that workers are full of energy, do sports and engage in positive relationships. The organization should promote and support such activities. What is more, the proper organization of office space, focusing on silence and the lack of factors that distract knowledge workers is equally important.

\section{Literature}

Clear, F. (2005). Teleworking practice in small and medium-sized firms: management style and worker autonomy. New Technology, Work and Employment, 20(3), 218-233, doi.org/10.1111/j/1468-005X.2005.00155.x.

Collins, C. (2017). Examining strategic fit and misfit in the management of knowledge workers. ILR Review, Sage Journals, 70(2), 308-335, doi.org/10.1177/0019793916654481.

Corso, M. (2006). Managing dispersed workers: the new challenge in Knowledge Management. Technovation, 26(5-6), 583-594. doi.org/10.1016/j.technovation.2005.02.003.

Davenport, T. H. (2005). Thinking for a Living: How to get better performance and results from knowledge workers. Boston: Harvard Business School Press.

Elliman, T., Eatock, T., Spencer, N. (2005). Modelling knowledge worker behaviour in business process studies. Journal of Enterprise Information Management, 18(1), 79-94. (5-6), 583-594. doi.org/10.1016/j.technovation.2005.02.003.

Drucker, P. (1999). Knowledge-worker productivity: The biggest challenge. California Management Review, 41(2), 79-94, doi.org/10.2307//41165987.

Felstead, A. (2017). Assesing the growth of remote working and its consequences for effort, well-being and work-life balance. New Technology, Work and Employment.

Glinka, B. i Pasieczny, J. (2015). Tworzenie Przedsiębiorstwa. Szanse, realizacja, rozwój. Warszawa: Wydawnictwa Uniwersytetu Warszawskiego.

Henard, D. (2008). Making knowledge workers more creative. Research - Technology Management, 51(2), 40-46, doi.org/10.1080/08956308.2008.11657494.

Herzberg, F. I. (1987). One more time: How do you motivate employees?, Harvard Business Review, 65(5), 109-120.

Howe, P. E., and Levin, M. C. (2007). Knowledge management is all about people, Pennsylvania CPA Journal.

Janz, B. (2003). Understanding the Antecedents of Effective Knowledge Management: The Importance of a Knowledge - Centered Culture. Decision Sciences, Journal (DSI), 14(2), 351-384, doi.org/10.1111/15405915.02328 .

Jayasingam, S. (2016). Instilling affective commitment: insights on what makes knowledge workers want to stay. Management Research Review, 39(3), 266-288, doi.org/10.1108/MRR-03-2014-0060.

Oskarsdottir, H. (2017). A Soft Systems Approach to Knowledge Worker Productivity - Analysis of the Problem Situation. Economies, 5(3), 28, doi.org/10.3390/economies5030028.

Pearce, C. (2004). The future of leadership: Combining vertical and shared leadership to transform knowledge work. Academy of Management Executive, 18(1), 47-59, www.jstor.org/sable/4166034.

Smith, K. (2005). Esixting knowledge, knowledge creation capability, and the rate of new product introduction in high-technology firms. Academy of Management Journal, 48(2), 346-357, doi.org10.2037/20159660.

Waters, N. (2012). An Empirical Study of Large-Sized Companies With Knowledge Work Teams and Their Impacts on Project Team Performance. Enginnering Management Journal, 24(2), 54-62, doi.org/10.1080/ 10429247.201211431936.

Wi, H. (2009). A team formation model based on knowledge and collaboration. Science Direct, 36(5), 9121 -9134, doi.org/10.1016/j.eswa.2008.12.031. 